\title{
CORRECTIONS
}

\section{Diagnosis and management of juvenile idiopathic arthritis}

We have been alerted to an error in drug dosage in this 2010 clinical review by Femke H M Prince and colleagues (BMJ 2010;341:c6434, doi:10.1136/bmj.c6434). In table 2 the leflunomide dose for children weighing $20-40 \mathrm{~kg}$ is quoted as $200 \mathrm{mg}$ orally for two days and then $10 \mathrm{mg}$ a day. The loading dose given is double what it should be. For this weight band the leflunomide dose is $100 \mathrm{mg}$ orally for two days and then $10 \mathrm{mg}$ a day.

Cite this as: $B M J 2011 ; 343: \mathrm{d} 4493$ 